made this way could be encased in plastic to form a stretchable, flexible electrical connection between light-emitting diodes.

Adv. Mater. http://

dx.doi.org/10.1002/

adma.201301400 (2013)

\section{PHYSIOLOGY}

\section{Bulging muscles gain strength}

A muscle that can bulge exerts more force than one held flat,

partly because of changes in the amount of space separating its fibres.

David Williams of the University of Washington in Seattle and his colleagues used X-ray diffraction measurements taken from insect flight muscles (a common model for skeletal muscle) to calibrate a theoretical model of contracting muscle. When muscles contract and bulge, the spreading that occurs between muscle fibres increases the angle at which muscle's thick myosin filaments tug on thin actin filaments, boosting the amount of force that can be exerted. Up to half of a muscle's peak strength can be accounted for by this mechanism, the researchers say.

Proc. R. Soc. B. 280, 20130697 (2013)

\section{CANCER BIOLOGY \\ Nerves spur prostate cancer}

The development of nerve fibres may encourage prostate cancer to grow and spread. Claire Magnon and Paul Frenette at the Albert Einstein College of Medicine in New York City and their colleagues used a battery of genetic, pharmacological and surgical techniques to disrupt specific interactions between nerves and tumours in a mouse model of prostate cancer. One type of nerve fibre promoted tumour growth through the neurotransmitter noradrenaline. Another type made cancer more invasive by releasing the neurotransmitter acetylcholine. An analysis of 43 human prostate-cancer samples found that more aggressive disease was correlated with more nerve fibres.

Interventions that block the growth of nerve tissue could provide a way to stall prostate cancer, the researchers suggest.

Science 341, 1236361 (2013)

For a longer story on this research, see go.nature.com/e2enib \section{SYMBIOSIS \\ Citrus pest's little helper}

A notorious agricultural pest harbours a bacterium that produces a toxin which may deter its predators.

Orange-grove farmers dread

the Asian citrus psyllid (Diaphorina citri), a small insect that carries the bacterial disease huanglongbing, which ruins citrus crops. Atsushi Nakabachi at Toyohashi University of Technology in Japan and his colleagues sequenced the genome of a second bacterium that lives inside the insect. Tentatively dubbed 'Candidatus Profftella armatura', the microbe's genome is so tiny that it can probably exist only within its host. About $15 \%$ of the genome is dedicated to the synthesis of a polyketide compound, which might protect the insect. The authors suggest that the genes that produce the toxic polyketide may have 'jumped' into the symbiont from another bacterial species.

Curr. Biol. http://dx.doi. org/10.1016/j.cub.2013.06.027 (2013)

\section{MOLECULAR BIOLOGY \\ Designer gene knockdowns}

A molecular tool borrowed from bacteria could provide a targeted way to switch genes on or off in human cells.

Species such as Streptococcus pyogenes can cleave DNA at

COMMUNITY CHOICE

The most viewed papers in science

\title{
Sounds of red blood cells
}

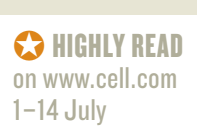

$1-14$ July

Eric Strohm and his colleagues at Ryerson University in Toronto, Canada, showed that when struck with a laser beam, red blood cells emit sound waves - albeit of a frequency too high for human ears to hear. Researchers used the amplitudes and frequencies of the waves to accurately determine the size and shape of these cells. The technique may one day be useful for diagnosing chemical imbalances, malaria, certain types of anaemia or other blood-related disorders, the authors say.

Biophys. J. 105, 59-67 (2013)

specified sites using a protein called Cas9 and strands of RNA that guide Cas9 to its target. Jonathan Weissman of the University of California, San Francisco, and his colleagues have modified this system to control transcription - the production of a specified RNA from its DNA template.

Although many guide RNAs were ineffective, the system worked in yeast and human cells, in one case reducing expression of a targeted human gene by up to $80 \%$ with minimal effects on other genes. The method, called CRISPR interference after the bacterial system it involves, can silence a wider variety of sequences than the popular RNA-interference technique.

Cell http://dx.doi.org/10.1016/j. cell.2013.06.044 (2013)

\section{ANIMAL BEHAVIOUR}

Cricket winners show off

Wild male crickets act more aggressively in fights and put on flashier victory displays if other crickets are watching.

Lauren Fitzsimmons and Susan Bertram at Carleton University in Ottawa placed pairs of male spring field crickets
(Gryllus veletis, pictured) together to fight. For some of the contests, the authors added a third cricket that could watch and hear the pair through a transparent, perforated wall. Wild-caught crickets' behaviour changed in the presence of spectators, becoming considerably more aggressive. Those that won fights also engaged in more flamboyant strutting (jerking their bodies and chirp-

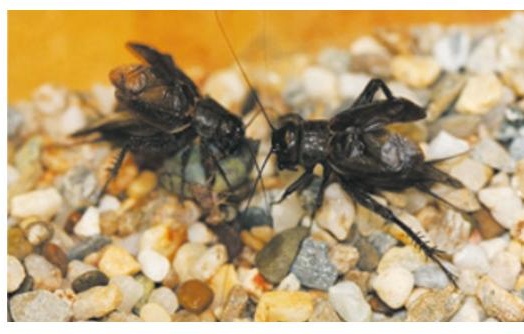

ing) if a third male cricket was present. Lab-reared crickets did not exhibit such marked behaviour, suggesting that it might be shaped by social experience.

Although audience effects are well-documented in vertebrates, this is the first evidence that invertebrates modify contest behaviour in the presence of an observer, the authors say.

Biol. Lett. 9, 20130449 (2013)

\section{DNATURE.COM}

For the latest research published by Naturevisit:

www.nature.com/latestresearch 